\title{
Epidemiological Characteristics, Ventilator Management, and Clinical Outcome in Patients Receiving Invasive Ventilation in Intensive Care Units from 10 Asian Middle-Income Countries (PRoVENT-iMiC): An International, Multicenter, Prospective Study
}

Luigi Pisani, ${ }^{1,2 \star}$ Anna Geke Algera, ${ }^{1}$ Ary Serpa Neto, ${ }^{1,3}$ Areef Ahsan, ${ }^{4}$ Abigail Beane, ${ }^{2}$ Kaweesak Chittawatanarat, ${ }^{5}$ Abul Faiz, ${ }^{2,6}$ Rashan Haniffa, ${ }^{3}$ Seyed MohammadReza Hashemian, ${ }^{7}$ Madiha Hashmi, ${ }^{8}$ Hisham Ahmed Imad, ${ }^{9}$ Kanishka Indraratna, ${ }^{10}$ Shivakumar lyer, ${ }^{11}$ Gyan Kayastha, ${ }^{12}$ Bhuvana Krishna, ${ }^{13}$ Tai Li Ling, ${ }^{14}$ Hassan Moosa, ${ }^{15}$ Behzad Nadjm, ${ }^{16}$

Rajyabardhan Pattnaik, ${ }^{17}$ Sriram Sampath, ${ }^{13}$ Louise Thwaites, ${ }^{18} \mathrm{Ni}$ Ni Tun, ${ }^{19}$ Nor'azim Mohd Yunos, ${ }^{20}$ Salvatore Grasso, ${ }^{21}$ Frederique Paulus, ${ }^{1}$ Marcelo Gama de Abreu, ${ }^{22}$ Paolo Pelosi, ${ }^{23,24}$ Nick Day, ${ }^{2,25}$ Nicholas J. White, ${ }^{2,25}$ Arjen M. Dondorp, ${ }^{2,25}$ and Marcus J. Schultz ${ }^{1,2,25,26}$ for the PRoVENT-iMiC Investigators, MORU, and the PROVE Network

${ }^{1}$ Department of Intensive Care, Amsterdam University Medical Centers, Location Academic Medical Center, Amsterdam, The Netherlands; ${ }^{2}$ Mahidol-Oxford Tropical Medicine Research Unit (MORU), Faculty of Tropical Medicine, Mahidol University, Bangkok, Thailand; ${ }^{3}$ Department of Critical Care Medicine, Hospital Israelita Albert Einstein, São Paulo, Brazil; ${ }^{4}$ Department of Critical Care, BIRDEM General Hospital, Dhaka, Bangladesh; ${ }^{5}$ Department of Surgery, Chiang Mai University, Chiang Mai, Thailand; ${ }^{6}$ Dev Care Foundation, Dhaka, Bangladesh; ${ }^{7}$ Chronic Respiratory Diseases Research Center (CRDRC), Shahid Beheshti University of Medical Sciences, Tehran, Iran; ${ }^{8}$ Department of Anaesthesiology, Aga Khan University, Karachi, Pakistan; ${ }^{9}$ Department of Clinical Tropical Medicine, Faculty of Tropical Medicine, Mahidol University, Bangkok, Thailand; ${ }^{10}$ Department of Anaesthesia and Intensive Care, Sri Jayewardenepura General Hospital, Colombo, Sri Lanka; ${ }^{11}$ Department of Medicine, Bharati Vidyapeeth Medical College, Pune, India; ${ }^{12}$ Department of Internal Medicine, Patan Academy of Health Science, Kathmandu, Nepal; ${ }^{13}$ Department of Critical Care Medicine, St. John's Medical College, Bangalore, India; ${ }^{14}$ Department of Anaesthesia and Intensive Care, Hospital Kuala Lumpur, Kuala Lumpur, Malaysia; ${ }^{15}$ Department of Intensive Care, Indira Gandhi Memorial Hospital, Malé, Maldives; ${ }^{16}$ National Hospital for Tropical Diseases, Oxford University Clinical Research Unit, Hanoi, Vietnam; ${ }^{17}$ Critical Care Unit, Ispat General Hospital, Rourkela, India; ${ }^{18} \mathrm{Hosp} i t a l$ for Tropical Diseases, Oxford University Clinical Research Unit, Ho Chi Minh City, Vietnam; ${ }^{19}$ Medical Action Myanmar, Naypyidaw, Myanmar;

${ }^{20}$ Department of Anaesthesiology, University of Malaya Medical Centre, Kuala Lumpur, Malaysia; ${ }^{21}$ Department of Emergency and Organ

Transplantation (DETO), University of Bari, Bari, Italy; ${ }^{22}$ Pulmonary Engineering Group, Department of Anaesthesiology and Intensive Care

Medicine, University Hospital Carl Gustav Carus, Technical University Dresden, Dresden, Germany; ${ }^{23}$ San Martino Policlinico Hospital - IRCCS for

Oncology, University of Genoa, Genoa, Italy; ${ }^{24}$ Department of Surgical Sciences and Integrated Diagnostics, University of Genoa, Genoa, Italy;

${ }^{25}$ Nuffield Department of Medicine, University of Oxford, Oxford, United Kingdom; ${ }^{26}$ Laboratory of Experimental Intensive Care and

Anaesthesiology (L.E.I.C.A) Amsterdam University Medical Centers, Location Academic Medical Center, Amsterdam, The Netherlands

Abstract. Epidemiology, ventilator management, and outcome in patients receiving invasive ventilation in intensive care units (ICUs) in middle-income countries are largely unknown. PRactice of VENTilation in Middle-income Countries is an international multicenter 4-week observational study of invasively ventilated adult patients in 54 ICUs from 10 Asian countries conducted in 2017/18. Study outcomes included major ventilator settings (including tidal volume [ $\left.V_{T}\right]$ and positive end-expiratory pressure [PEEP]); the proportion of patients at risk for acute respiratory distress syndrome (ARDS), according to the lung injury prediction score (LIPS), or with ARDS; the incidence of pulmonary complications; and ICU mortality. In 1,315 patients included, median $V_{T}$ was similar in patients with LIPS $<4$ and patients with LIPS $\geq 4$, but lower in patients with ARDS (7.90 [6.8-8.9], 8.0 [6.8-9.2], and 7.0 [5.8-8.4] mL/kg Predicted body weight; $P=0.0001)$. Median PEEP was similar in patients with LIPS $<4$ and LIPS $\geq 4$, but higher in patients with ARDS (five [5-7], five [5-8], and 10 [5-12] $\left.\mathrm{CmH}_{2} \mathrm{O} ; P<0.0001\right)$. The proportions of patients with LIPS $\geq 4$ or with ARDS were $68 \%(95 \% \mathrm{Cl}: 66-71)$ and $7 \%(95 \% \mathrm{Cl}$ : $6-8)$, respectively. Pulmonary complications increased stepwise from patients with LIPS $<4$ to patients with LIPS $\geq 4$ and patients with ARDS $(19 \%, 21 \%$, and $38 \%$ respectively; $P=0.0002)$, with a similar trend in ICU mortality $(17 \%, 34 \%$, and $45 \%$ respectively; $P<0.0001$ ). The capacity of the LIPS to predict development of ARDS was poor (receiver operating characteristic [ROC] area under the curve [AUC] of $0.62,95 \% \mathrm{Cl}: 0.54-0.70)$. In Asian middle-income countries, where two-thirds of ventilated patients are at risk for ARDS according to the LIPS and pulmonary complications are frequent, setting of $V_{T}$ is globally in line with current recommendations.

\section{INTRODUCTION}

Although invasive ventilation is an essential part of critical care and can be a life-saving intervention, it also has strong potential to cause or worsen lung injury. ${ }^{1}$ The risk of the socalled ventilator-induced lung injury can be substantially reduced by applying lung-protective ventilation including a low tidal volume $\left(V_{T}\right)$ and a sufficient positive end-expiratory pressure (PEEP). Two recent worldwide observational studies suggest improvements in ventilator management over recent decades, such as lower $V_{T}$ and higher PEEP, confirming trends observed in earlier service reviews. ${ }^{2-6}$ The recent

*Address correspondence to Luigi Pisani, Department of Intensive Care, Amsterdam University Medical Centers, Location AMC, Meibergdreef 9, Amsterdam 1105 AZ, The Netherlands. E-mail: luigipisani@gmail.com
"PRactice of VENTilation (PRoVENT) in critically ill patients without acute respiratory distress syndrome (ARDS)" study ${ }^{7}$ and the "Large observational study to UNderstand the Global impact of Severe Acute respiratory Failure" (LUNG SAFE) ${ }^{8}$ showed more than half of patients receiving protective ventilation.

Evidence for benefit and implementation of protective ventilation is mostly from high-income countries. ${ }^{2-4,7-9}$ It is uncertain to what extent protective ventilation is being practiced in middle-income countries, where intensive care units (ICUs) and thus invasive ventilation are increasingly becoming available. Participation of Asian middle-income country ICUs in recent multinational ventilation studies has been scant. ${ }^{4,7}$ Few subnational studies explored the practice of ventilation showing variable adoption of protective ventilation. ${ }^{5,10}$ This limitation may lead to a deficient insight on actual use of protective ventilation in resource-limited ICUs. Significant 
differences with regard to practice of care affect resourcelimited settings that go beyond the context-specific patient case mix. ${ }^{10}$ Challenges to deliver high-quality ventilation involve equipment itself, as inaccurate flowmeters or malfunctioning sensors hinder ventilator's reliability. Further challenges derive from monitoring, including continuous pulse oximetry, capnography, repeated blood gas analysis, and blood pressure measurements, as well as human resources and a proper infrastructure. ${ }^{11,12}$ These challenges may make invasive ventilation less safe and may hamper implementation of protective ventilation.

The current study aimed to describe current practices of invasive ventilation in ICUs in Asian middle-income countries as well as the epidemiological characteristics and disease outcome of patients receiving invasive ventilation. We performed an international multicenter prospective 4-week cohort study and describe associations between ventilator settings and patient-centered outcomes. We hypothesized that ventilation practices do not routinely include lungprotective settings like a low $V_{T}$ and sufficient PEEP; however, a high number of patients are at risk for or have ARDS.

\section{METHODS}

Study design and participants. PRactice of VENTilation in Middle-income Countries is an investigator-initiated international multicenter prospective cohort study in consecutive ICU patients receiving invasive ventilation during a predefined 4-week period. Patients were recruited in 54 ICUs from 10 Asian countries (a complete list can be found in Supplemental Appendix, p. 3). The study protocol has been published previously, ${ }^{13}$ and the current report follows the Strengthening the Reporting of Observational Studies in Epidemiology statement. ${ }^{14}$

Participating centers were recruited through national coordinators with help from the members of PRoVENT-iMiC steering committee. Ethics review by the Oxford Tropical Research Ethical Committee on June 9, 2017 designated this study as minimal risk. National and local ethics committees of participating centers, where applicable, approved a waiver of patient-level consent.

Patients who started invasive ventilation in the ICU during the inclusion period were eligible for participation. However, patients who started invasive ventilation in the emergency room, the clinical ward, within the community or in the operating room directly preceding the present ICU admission were also eligible for participation, independently from the number of hours spent under invasive ventilation in these settings. There was no minimum time of invasive ventilation in the participating ICU required to be included in the study. We excluded patients younger than 18 years, patients who received noninvasive ventilation (NIV) not followed by invasive ventilation, patients whose invasive ventilation started before the inclusion period of PRoVENT-iMiC, and patients transferred from another hospital while receiving invasive ventilation.

Procedures. At the discretion of the national coordinators, each country or region selected a recruitment period of 28 consecutive days. If possible, the period was the same for all centers in one country or region. Site investigators were responsible for patient recruitment and follow-up until ICU discharge. The study endpoint was censored at 60 days postadmission for patients still in the ICU at this time point.
National coordinators assisted site investigators and monitored the study according to GCP-guidelines, ensuring integrity and timely completion of data collection. Before the initiation of the study, the national coordinators reviewed the case report forms (CRFs) to evaluate clarity and consistency (see Supplemental Appendix, pp. 24-38). A concise one-off web-based survey on ICU structure and organizational aspects was performed in the participating sites, as suggested by previous literature ${ }^{12}$ (see Supplemental Appendix, pp. 39-44).

An extended dataset was collected daily until day 7 and at discharge from the ICU. We defined the first calendar day the patient received invasive ventilation in the ICU as day 0 , irrespective of ICU admission date and location of initial intubation. Baseline and demographic variables were collected on the day of admission, including data for calculation of the Sequential Organ Failure Assessment Score (SOFA) and the Lung Injury Prediction Score (LIPS). ${ }^{15}$ The presence of ARDS was scored by the site investigators according to the Berlin Definition for ARDS, ${ }^{16}$ with the option of stratifying the oxygenation defect according to oxygen saturation $\left(\mathrm{SpO}_{2}\right)$ / inspired fraction of oxygen $\left(\mathrm{FiO}_{2}\right)$ instead of Oxygen partial pressure $\left(\mathrm{PaO}_{2}\right) / \mathrm{FiO}_{2}$ cutoffs. ${ }^{17-19}$ Thereafter, each day for the first 3 days of ventilation, around 08:00 hours, ventilation variables and parameters, neurological status, and basic hemodynamic parameters were recorded. Every day until day 7 , ICU discharge, or death, the occurrence of predefined pulmonary complications was scored. Pulmonary complications reported in the first 24 hours of invasive ventilation were excluded from main analysis and reported separately (Supplemental Appendix, p. 14), as may have represented the potential reason for intubation. Site investigators also recorded rescue therapies for refractory hypoxemia, including use of neuromuscular blockers, recruitment maneuvers, and prone positioning.

Patient data were entered into a password-secured, Internetbased, electronic CRF (Research Electronic Data Capture, www.projectredcap.org). Before analysis, investigators screened all data for potentially erroneous or incomplete recordings and verified and corrected information as appropriate.

Outcomes. The study outcomes were represented by main ventilator settings, including $V_{T}$ and PEEP; additional ventilation variables and parameters, including oxygen fraction of inspired $\operatorname{air}\left(\mathrm{FiO}_{2}\right)$, respiratory rate $(\mathrm{RR})$, peak inspiratory airway pressure, plateau, and driving pressure (Ppeak, plateau airway pressure [Pplat], and driving pressure); the proportion of patients at risk for or with ARDS; incidence of pulmonary complications, including pneumonia, ARDS after start of invasive ventilation, pneumothorax, pleural effusion, atelectasis, and cardiogenic pulmonary edema (for definitions, see Supplemental Appendix, p. 5); length of stay in the ICU; and all-cause ICU mortality.

Statistical analysis. The statistical analysis plan was published before locking of the database, ${ }^{13}$ and the final version was uploaded at clinicaltrials.gov before the end of enrolment. Modifications from the original analysis plan are detailed in Supplemental Appendix, p. 6. No formal sample size calculation was performed, but the predicted sample size $(>1,200$ patients) based on the allocated time period and a minimum expected enrolment rate of 20 patients/center was deemed sufficient to provide meaningful conclusions.

Data on ventilation variables and parameters are presented in full detail for the day of start of invasive ventilation, and for 
the successive 3 days. Predicted body weight (PBW) of male patients was calculated as $50+0.91 \times$ (height $[\mathrm{cm}]-152.4)$ and for female patients as $45.5+0.91 \times$ (height [cm] - 152.4). Driving pressure was calculated by subtracting PEEP from the Pplat (in volume-controlled ventilation) or maximum airway pressure (Pmax) (in pressure-controlled ventilation). Scatterplots were used to present distributions of $V_{T}$ versus PEEP, $V_{T}$ versus $R R, V_{T}$ versus Pplat, and $V_{T}$ versus driving pressure. Cutoffs for ventilator parameters were based on widely accepted published values, ${ }^{7,8,20}$ including $8 \mathrm{~mL} / \mathrm{kg}$ PBW for $V_{T}$, $5 \mathrm{cmH}_{2} \mathrm{O}$ for PEEP, 14 breaths/minute for $\mathrm{RR}, 30 \mathrm{cmH}_{2} \mathrm{O}$ for Pplat, and $15 \mathrm{cmH}_{2} \mathrm{O}$ for driving pressure. ${ }^{7}$

Patients were stratified in three groups for comparison of the study endpoints: patients with LIPS on day 0 lower than 4 (i.e., not at risk of ARDS according to the LIPS), patients with a LIPS of 4 or more (at risk of ARDS according to the LIPS, but not fulfilling the criteria for ARDS), and patients with ARDS diagnosed by the attending physician at the start of ventilation. The proportion of patients with LIPS $\geq 4$, or with ARDS, was calculated by dividing the number of patients with LIPS $\geq$ 4 , or with ARDS, by the total number of patients. The number of patients of patients with LIPS $\geq 4$, or with ARDS, was derived per ICU bed over the study period by dividing the number of patients of patients with LIPS $\geq 4$, or with ARDS, by the number of ICU beds available.

The number of patients developing one or more pulmonary complications during the first 7 days following start of invasive ventilation and patient outcomes at ICU discharge were reported in absolute numbers and percentages. Each new pulmonary complication was accounted for only once, considering the day of insurgence as the first day it was reported. A competing risk analysis based on cumulative incidence functions and "Fine and Gray" proportional sub-distribution hazards analysis was used to model the probability of discontinuing mechanical ventilation in the presence of the competing risk of death.

Univariable and multivariable analyses were performed to identify risk factors associated with ICU mortality and development of pulmonary complications. Covariates for the univariable models were included based on clinical relevance or the presence of imbalance at baseline. These included, but were not limited to, ventilator settings (in particular $V_{T}$ and PEEP at day 0). Covariates included in the final mixed-effect multivariable models were identified as those with $P<0.2$ in the univariable model (including participating center as a random effect), and not statistically associated with other included variables. Linearity assumption was assessed plotting the logit $x$ the predictor values (Supplemental Appendix, p. 23). Thus, nonlinear variables were entered as categorical variables (according to original categories or newly categorized). Pearson correlation coefficients were used to assess collinearity between predictors. Since a high level of collinearity among Ppeak, Pplat, and driving pressure was expected, the main model included the variable with the higher amount of measurements between Ppeak and Pplat. Driving pressure was considered separately in a sensitivity analysis, excluding PEEP, Ppeak, and Pplat. Finally, the intraclass correlation coefficient was assessed, representing the ratio of betweensite variance to total variance, ranging from 0 to 1 . Multiple imputations of missing values were not performed because of the low number of missing values for the variables considered (see Supplemental Appendix, p. 7). For the models exploring
ICU mortality, age and PEEP did not meet the linearity assumption and were entered as categorical variables. For the models exploring pulmonary complications, pulmonary SOFA, PEEP, Ppeak, and LIPS did not meet the linearity assumption (Supplemental Appendix, p. 23). Thus, pulmonary SOFA was entered as a categorical variable (according to original categories), whereas Ppeak, PEEP, and LIPS were categorized according to clinically meaningful categories. Sequential organ failure assessment score, $\mathrm{FiO}_{2}, \mathrm{PaO}_{2} / \mathrm{FiO}_{2}$, and $\mathrm{SpO}_{2} / \mathrm{FiO}_{2}$ were excluded from the multivariable analysis because of relationship and multicollinearity with pulmonary SOFA. $\mathrm{HCO}_{3}$ was excluded because of multicollinearity with $\mathrm{pH}$.

In test groups of continuous normally distributed variables, Student's $t$-test and analysis of variance analysis were used. Likewise, the Mann-Whitney $U$ test was used in case of not normally distributed data. Categorical variables were compared with the chi-square test or Fisher's exact test. Statistical uncertainty was expressed by $95 \% \mathrm{Cl}$. To account for the potential clustering of observations in participating centers, an additional analysis comparing ventilatory variables and outcomes in the three study groups was performed using linear (for numerical variables) and logistic (for categorical variables) mixed-effects models, with center as the random effect. A $P$ value of less than 0.05 was considered statistically significant. We did not correct for multiplicity across analyses; hence, the findings should be seen as exploratory. Statistical analysis was conducted using $R$ (www.r-project.org, $R$ version 3.3.1). The study was registered at clinicaltrials.gov, NCT 03188770.

Role of the funding source. External funding source for this study was sought only in Vietnam (Wellcome Trust grants 107367/Z/15/Z and 089276/B/09/7). The first two authors and Steering Committee members had full access to all studyrelated data and had final responsibility to submit this report for publication.

\section{RESULTS}

Study sites and patients characteristics. Of 65 ICUs in 11 countries that expressed interest in the study, 54 ICUs from 10 countries took part in the study, including 1,315 patients between November 2017 and December 2018 (Figure 1). Patient characteristics are shown in Table 1; ICU organizational characteristics and available resources are detailed in Supplemental Appendix, pp. 4-5. Three of four centers were public government hospitals, mostly serving a mixed population of surgical and medical patients from both urban and rural settings.

Risk and prevalence of ARDS. Of the included patients, 389 patients (29.6\%, 95\% Cl: 27.1-32.1) had a LIPS < 4, 837 patients $(63.7 \%, 95 \% \mathrm{Cl}: 61.1-66.3)$ had a LIPS $\geq 4$, and 89 patients $(6.8 \%, 95 \% \mathrm{Cl}: 5.8-8.2)$ had ARDS at the start of invasive ventilation (Table 1), and their distribution showed substantial geographical variation (Supplemental Appendix, p. 9). Patients with LIPS $\geq 4$ and patients with ARDS represented 0.88 and 0.09 cases per ICU bed over a 4-week period, respectively. Of the patients with ARDS at study onset, $26 \%$ had mild ARDS, $27 \%$ had moderate ARDS, and the remaining patients had severe ARDS. Of note, one of 10 patients were ventilated for more than 12 hours in a clinical ward before being admitted to the ICU, highlighting the issue of accessibility and shortage of ICU beds in these settings. 


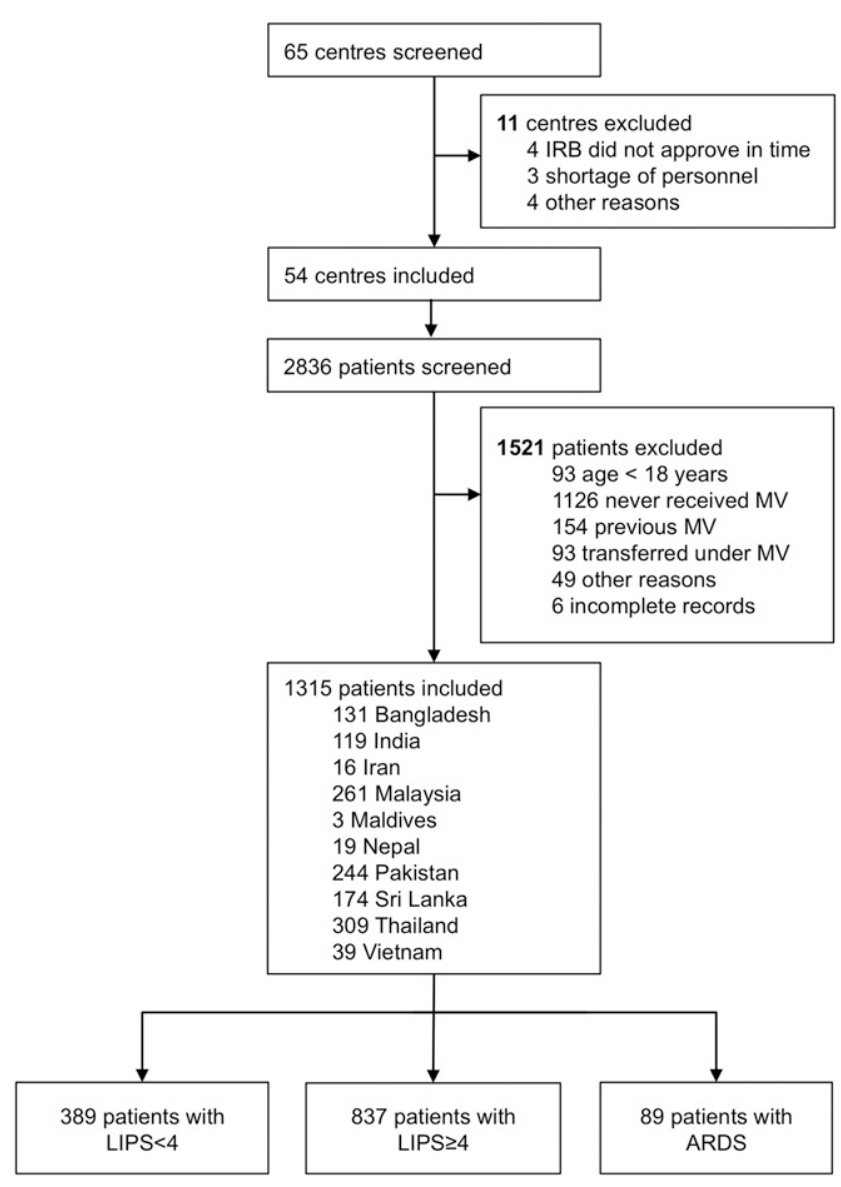

FIGURE 1. Screening and enrolment. ARDS = acute respiratory distress syndrome; IRB = institutional review board; LIPS = lung injury prediction score; $\mathrm{MV}=$ mechanical ventilation.

Ventilation management. The median and modus absolute $V_{T}$ of $450(400-500) \mathrm{mL}$ and $500 \mathrm{~mL}$ resulted in a $V_{T}$ of 7.8 (6.8-9.1) $\mathrm{mL} / \mathrm{kg}$ PBW (Table 2). Tidal volume was similar in patients with LIPS $<4$ and patients with LIPS $\geq 4$, but was lower in patients with ARDS. Tidal volume was greater than 8.0 $\mathrm{mL} / \mathrm{kg}$ PBW in $45 \%$ of patients with LIPS $<4$, in $50 \%$ of patients with LIPS $\geq 4$, and in $33 \%$ of patients with ARDS (Figure 2A). A $V_{T} \leq 7 \mathrm{~mL} / \mathrm{kg} / \mathrm{PBW}$ was found in one-third of patients without ARDS, but in more than half of patients with ARDS. The variance of $V_{T}$ when expressed in $\mathrm{mL} / \mathrm{kg}$ PBW was large in all centers across countries (Supplemental Appendix, p. 19). Median and mode PEEP was five (5-8) $\mathrm{cmH}_{2} \mathrm{O}$ and $5 \mathrm{cmH}_{2} \mathrm{O}$, respectively. Positive end-expiratory pressure was similar in patients with LIPS $<4$ and LIPS $\geq 4$, but was higher in patients with ARDS (Figure 2B). Although approximately twothirds of patients without ARDS were ventilated with a PEEP of $5 \mathrm{cmH}_{2} \mathrm{O}$ or less, this happened only in one-third of patients with ARDS. Distributions of $V_{T}$ against various ventilator parameters are shown in eFigure 2 (Supplemental Appendix, $p$. $20)$. Roughly $50 \%$ of patients received invasive ventilation within the limits of what is generally accepted as lungprotective ventilation (Supplemental Appendix, p. 20, panel A). The lower $V_{T}$ used in ARDS patients was accompanied by the use of higher set and measured RRs, although extreme values (i.e. $R R>30$ ) were seldom used (Table 2 and Supplemental Appendix, p. 20, panel C). When the clustering of observations in participating centers is considered, differences in $V_{T}$ among the three study groups were not significant anymore (Supplemental Appendix, pp. 17-18).

Volume-controlled ventilation and synchronized intermittent mandatory ventilation were the two most commonly used ventilation modes (Table 2 and Supplemental Appendix, pp. 9-11, and 21). Pressure-controlled ventilation was used in about one-fourth of patients, and was the most prevalent mode in patients with ARDS. Median $\mathrm{FiO}_{2}, \mathrm{RR}$, Ppeak, and Pplat (Figure 2C) increased from patients with LIPS $<4$ to patients with LIPS $\geq 4$ and patients with ARDS. Differences in ventilator parameters sustained during the first 3 days of invasive ventilation (Figure 3 ). In longitudinal analysis, an interaction between time and study group was found only for $\mathrm{FiO}_{2}$ and Pplat; that is, there was a greater decrease of oxygen supplementation in ARDS, whereas Pplat decreased only slightly in ARDS and remained constant for the other two groups. Median driving pressure was similar in patients with LIPS $<4$ and patients with LIPS $\geq 4$, but was higher in patients with ARDS (Figure 2D).

Pulmonary complications. Overall, one-fifth of patients developed one or more pulmonary complications during the first 7 days of ICU stay (Table 3 and Supplemental Appendix, pp. 12-13). Pulmonary complication rates were similar in patients with LIPS $<4$ and LIPS $\geq 4$, but was higher in patients with ARDS. Of all patients without ARDS at the start of ventilation, 51 (4\%) developed ARDS during the first 7 days of ICU stay, mostly on day 1 or 2 , with no significant difference between patients with LIPS $<4$ and LIPS $\geq 4(P=0.151)$. The capacity of the LIPS to predict development of ARDS was poor (ROC AUC of 0.62, 95\% Cl: 0.54-0.70; Supplemental Appendix, p. 27). Overall, $7 \%$ of patients underwent tracheostomy ( $14 \%$ in patients with ARDS), whereas $4 \%$ needed re-intubation after an unsuccessful extubation attempt. The frequency of tracheostomy was different among the three groups.

Patient outcomes. When mortality in the three groups is taken as a competing risk, at any particular time, patients with LIPS $\geq 4$ were $27 \%$ less likely, and patients with ARDS were $45 \%$ less likely to be extubated than patients with LIPS $<4$ (Figure 4). Almost half of patients with ARDS died in ICU, compared with a third of patients with LIPS $\geq 4$ and less than a sixth of patients with LIPS $<4$. The duration of invasive ventilation was longer in ARDS patients, whereas the length of stay in ICU did not differ between the three patient groups (Table 3). Length of stay in non-surviving patients was shorter of roughly 1 day than that of surviving patients.

Adjunctive treatments were infrequently used, except for muscle paralysis that was used in approximately one in every five patients, and was about twice more frequent in patients with ARDS. Recruitment maneuvers and prone positioning were used infrequently and mostly in patients with ARDS. None of the patients in this study received extracorporeal membrane oxygenation or other extracorporeal techniques.

Univariable and multivariable analyses of factors associated with ICU mortality and pulmonary complications are listed in Table 4 and Supplemental Appendix, pp. 15-16. According to all models and based on clinical relevance, age, non-pulmonary SOFA, LIPS, Ppeak, heart rate, $\mathrm{pH}$, and previous use of NIV before intubation were selected as potential predictors of death in ICU. Pulmonary SOFA, arterial pH levels, and chronic liver failure were consistently selected as potential predictors of pulmonary complications. 
TABLE 1

Baseline patient characteristics

\begin{tabular}{|c|c|c|c|c|c|c|}
\hline & All patients $(n=1,315)$ & LIPS < $4(n=389)$ & LIPS $\geq 4(n=837)$ & $\begin{array}{l}\text { Acute respiratory } \\
\text { distress syndrome } \\
(n=89)\end{array}$ & $\begin{array}{c}P \text {-value } \\
\text { LIPS }<4 \text { vs. } \\
\text { LIPS } \geq 4\end{array}$ & $P$-value ${ }^{*}$ \\
\hline Age (years) & $57[40,67]$ & $54[37,66]$ & $58[42,68]$ & $49[35,62]$ & 0.018 & 0.0013 \\
\hline Gender, female & $507 / 1,314(38.6)$ & $159(40.9)$ & $317 / 836$ (37.9) & $31(34.8)$ & 0.355 & 0.462 \\
\hline $\begin{array}{l}\text { Sequential Organ Failure Assessment } \\
\text { score } \dagger\end{array}$ & $7[5,10]$ & $6[4,8]$ & $8[6,11]$ & $9[6,12]$ & $<0.001$ & $<0.0001$ \\
\hline LIPS $\ddagger$ & $5[3.5,7]$ & $2.5[2,3.5]$ & $6[5,8]$ & $7.5[6,8.5]$ & $<0.001$ & $<0.0001$ \\
\hline Height (cm) & $163[156,170]$ & $165[158,170]$ & $162[155,170]$ & $165[160,170]$ & 0.07 & 0.087 \\
\hline Weight (kg) & $64[55,72]$ & $62[55,72]$ & $65[55,73]$ & $63[55,72]$ & 0.109 & 0.259 \\
\hline Predicted body weight (kg) & $58[50.6,66]$ & $59[51,66]$ & $57[49,66]$ & $60[52,66]$ & 0.167 & 0.185 \\
\hline Body mass index $\left(\mathrm{kg} / \mathrm{m}^{2}\right)$ & $23.7[21.5,26.9]$ & $23.4[21.3,26.4]$ & $23.9[21.7,27.3]$ & $23.3[20.8,25.7]$ & 0.016 & 0.0134 \\
\hline \multicolumn{7}{|l|}{ Ventilation status } \\
\hline Ventilation in ward before admission & $144 / 1,314(11.0)$ & 43/388 (11.1) & $97(11.6)$ & $4(4.5)$ & 0.871 & 0.125 \\
\hline NIV before invasive ventilation & 191/1,312 (14.6) & $26 / 388(6.7)$ & $124 / 835(14.9)$ & $41(46.1)$ & $<0.001$ & $<0.0001$ \\
\hline NIV duration (minutes) & $180[36,660]$ & $180[70,960]$ & $172[30,600]$ & $220[62,765]$ & 0.172 & 0.262 \\
\hline Reason for ICU admission, $n(\%)$ & & & & & $<0.001$ & $<0.001$ \\
\hline Planned surgery & $246(18.7)$ & $112(28.8)$ & $132 / 836(15.8)$ & $2(2.2)$ & & \\
\hline Emergency surgery (excl. trauma) & $145(11.0)$ & $31(8.0)$ & $107 / 836(12.8)$ & $7(7.9)$ & & \\
\hline Trauma & $76(5.8)$ & $9(2.3)$ & $62 / 836(7.4)$ & $5(5.6)$ & & \\
\hline Medical condition & $847(64.5)$ & 237 (60.9) & $535 / 836(64.0)$ & $75(84.3)$ & & \\
\hline Admission source & & & & & 0.036 & $<0.0001$ \\
\hline Emergency department & 405/1,305 (31.0) & 122/386 (31.6) & $250 / 830(30.1)$ & $33(37.1)$ & & \\
\hline Operating room & 340/1,305 (26.1) & 118/386 (30.6) & $216 / 830(26.0)$ & $6(6.7)$ & & \\
\hline Medical or surgical ward & 462/1,305 (35.4) & $114 / 386(29.5)$ & $303 / 830$ (36.5) & $45(50.6)$ & & \\
\hline Obstetric ward & $26 / 1,305(2.0)$ & 4/386 (1.0) & $20 / 830(2.4)$ & $2(2.2)$ & & \\
\hline Directly from community & $7 / 1,305(0.5)$ & 4/386 (1.0) & $3 / 830(0.4)$ & $0(0.0)$ & & \\
\hline Other hospital or ICU & $65 / 1,305(5.0)$ & 24/386 (6.2) & $38 / 830(4.6)$ & $3(3.4)$ & & \\
\hline Smoking status & & & & & 0.015 & 0.0325 \\
\hline Never & 665/1,314 (50.6) & $211(54.2)$ & $401 / 836(48.0)$ & $53(59.6)$ & & \\
\hline Former & 216/1,314 (16.4) & 46 (11.8) & 157/836 (18.8) & $13(14.6)$ & & \\
\hline Current & 156/1,314 (11.9) & $44(11.3)$ & 104/836 (12.4) & $8(9.0)$ & & \\
\hline Unknown & 277/1,314 (21.1) & $88(22.6)$ & 174/836 (20.8) & 15 (16.9) & & \\
\hline \multicolumn{7}{|l|}{ Reason for intubation, $n(\%) \S$} \\
\hline Cardiac arrest & $72(5.5)$ & $14(3.6)$ & $57(6.8)$ & $1(1.1)$ & 0.035 & 0.0124 \\
\hline Anaesthesia for surgery & $328(24.9)$ & $122(31.4)$ & 200 (23.9) & $6(6.7)$ & 0.007 & $<0.0001$ \\
\hline Hemodynamic instability & $186(14.1)$ & $33(8.5)$ & $132(15.8)$ & $21(23.6)$ & 0.001 & $<0.0001$ \\
\hline Other & $96(7.3)$ & $42(10.8)$ & $51(6.1)$ & $3(3.4)$ & 0.005 & 0.0044 \\
\hline Depressed level of consciousness & $351(26.7)$ & 124 (31.9) & $215(25.7)$ & $12(13.5)$ & 0.029 & 0.0011 \\
\hline Acute respiratory failure & $522(39.7)$ & $78(20.1)$ & 367 (43.8) & 77 (86.5) & $<0.001$ & $<0.0001$ \\
\hline Cause of acute respiratory failure & & & & & & $<0.0001$ \\
\hline Community acquired pneumonia & $113 / 522(21.6)$ & $14 / 78(17.9)$ & $85 / 367(23.2)$ & 14/77 (18.2) & & \\
\hline Nosocomial pneumonia & $45 / 522(8.6)$ & 3/78 (3.8) & $38 / 367(10.4)$ & $4 / 77(5.2)$ & & \\
\hline Unplanned postoperative ventilation & 9/522 (1.7) & $2 / 78(2.6)$ & $6 / 367(1.6)$ & $1 / 77(1.3)$ & & \\
\hline Cardiogenic pulmonary oedema & $65 / 522(12.5)$ & $12 / 78(15.4)$ & $51 / 367(13.9)$ & $2 / 77(2.6)$ & & \\
\hline Sepsis (other than pneumonia) & $98 / 522(18.8)$ & $10 / 78(12.8)$ & $79 / 367(21.5)$ & 9/77 (11.7) & & \\
\hline COPD exacerbation & $42 / 522(8.0)$ & $10 / 78(12.8)$ & $32 / 367(8.7)$ & $0 / 77(0.0)$ & & \\
\hline Other & $112 / 522(21.5)$ & $27 / 78(34.6)$ & $76 / 367(20.7)$ & 9/77 (11.7) & & \\
\hline \multicolumn{7}{|l|}{ Chronic comorbidities, $n(\%) \|$} \\
\hline None & $359(27.3)$ & $124(31.9)$ & $204(24.4)$ & $31(34.8)$ & 0.007 & 0.0059 \\
\hline Arterial hypertension & $533(40.5)$ & $150(38.6)$ & $357(42.7)$ & $26(29.2)$ & 0.196 & 0.0314 \\
\hline Heart failure & $104(7.9)$ & $22(5.7)$ & 77 (9.2) & $5(5.6)$ & 0.045 & 0.0718 \\
\hline Diabetes mellitus & $392(29.8)$ & $96(24.7)$ & $278(33.2)$ & $18(20.2)$ & 0.003 & 0.0012 \\
\hline Chronic kidney disease & $175(13.3)$ & $46(11.8)$ & $117(14.0)$ & $12(13.5)$ & 0.346 & 0.586 \\
\hline Liver cirrhosis & $58(4.4)$ & $13(3.3)$ & $41(4.9)$ & $4(4.5)$ & 0.277 & 0.466 \\
\hline COPD & $84(6.4)$ & $18(4.6)$ & $61(7.3)$ & $5(5.6)$ & 0.101 & 0.198 \\
\hline Cancer & $118(9.0)$ & $31(8.0)$ & $79(9.4)$ & $8(9.0)$ & 0.465 & 0.704 \\
\hline Neuromuscular disease & 17 (1.3) & $7(1.8)$ & $9(1.1)$ & $1(1.1)$ & 0.442 & 0.573 \\
\hline Other & $212(16.1)$ & 62 (15.9) & 133 (15.9) & $17(19.1)$ & 1 & 0.731 \\
\hline
\end{tabular}

\section{DISCUSSION}

In this international, multicenter, observational study in ICUs in Asian countries, two-thirds of patients undergoing invasive ventilation were at risk for ARDS, according to the
LIPS, whereas only a minority of patients actually had ARDS at the start of ventilation. Individualization of $V_{T}$ was applied poorly, but applied $V_{T}$ levels in these limited-resource settings were globally compatible with lung-protective ventilation. A $V_{T}<8 \mathrm{~mL} / \mathrm{kg}$ PBW was applied in a majority of patients with 
TABLE 2

Ventilation characteristics in the first day of mechanical ventilation

\begin{tabular}{|c|c|c|c|c|c|c|}
\hline & All patients $(n=1,315)$ & LIPS $<4(n=389)$ & LIPS $\geq 4(n=837)$ & $\begin{array}{l}\text { Acute respiratory } \\
\text { distress syndrome } \\
(n=89)\end{array}$ & $\begin{array}{l}P \text {-value } \\
\text { LIPS }<4 \text { vs. } \\
\text { LIPS } \geq 4\end{array}$ & $P$-value ${ }^{*}$ \\
\hline Absolute $V_{T}(\mathrm{~mL})$ & $450[400,500]$ & $450[400,500]$ & $450[400,500]$ & $400[360,470]$ & 0.642 & 0.0001 \\
\hline Absolute $V_{T}(\mathrm{~mL})$ mode & 500 & 500 & 500 & 400 & - & - \\
\hline$V_{T}$ PBW (mL/kg PBW) & $7.9[6.8,9.1]$ & $7.9[6.8,8.9]$ & $8.0[6.8,9.2]$ & $7.0[5.8,8.4]$ & 0.621 & 0.0001 \\
\hline Controlled mode & $7.9[6.8,9.1]$ & $7.9[6.8,8.9]$ & $8.0[6.8,9.2]$ & $7.0[5.8,8.5]$ & 0.765 & 0.0002 \\
\hline Spontaneous mode & $8.1[7.0,9.2]$ & $7.8[6.5,9.5]$ & $8.3[7.4,9.3]$ & $7.7[7.1,8.0]$ & 0.372 & 0.4113 \\
\hline$\leq 7.0$ & $396(30.5)$ & $111(28.8)$ & $240(29.2)$ & $45(50.6)$ & 0.0715 & 0.0002 \\
\hline $7.1-8.9$ & 561 (43.2) & $181(46.9)$ & $350(42.5)$ & $30(33.7)$ & - & - \\
\hline $9.0-10.0$ & $143(11.0)$ & $31(8.0)$ & 107 (13.0) & $5(5.6)$ & - & - \\
\hline$>10.0$ & 198 (15.3) & 63 (16.3) & $126(15.3)$ & $9(10.1)$ & - & - \\
\hline$V_{T}$ actual body weight $(\mathrm{mL} / \mathrm{kg})$ & $7.0[6.0,8.2]$ & $7.1[6.2,8.3]$ & $7.0[6.0,8.1]$ & $6.4[5.6,7.3]$ & 0.016 & 0.0001 \\
\hline Positive end-expiratory pressure $\left(\mathrm{cmH}_{2} \mathrm{O}\right)$ & $5.0[5.0,8.0]$ & $5.0[5.0,7.0]$ & $5.0[5.0,7.5]$ & $10.0[5.0,12.0]$ & 0.123 & $<0.0001$ \\
\hline$\leq 5$ & $804(61.1)$ & $261(67.1)$ & $520(62.1)$ & $23(25.8)$ & 0.232 & $<0.0001$ \\
\hline $6-8$ & $335(25.5)$ & $94(24.2)$ & $220(26.3)$ & $21(23.6)$ & - & - \\
\hline $8-10$ & $112(8.5)$ & $27(6.9)$ & $69(8.2)$ & $16(18.0)$ & - & - \\
\hline$>10$ & $64(4.9)$ & $7(1.8)$ & $28(3.3)$ & 29 (32.6) & - & - \\
\hline Ventilation mode, $n(\%)$ & & & & & 0.0077 & 0.0001 \\
\hline Volume controlled & $483(36.7)$ & $171(44.0)$ & $288(34.4)$ & $24(27.0)$ & - & - \\
\hline Pressure controlled & $327(24.9)$ & $80(20.6)$ & $218(26.0)$ & 29 (32.6) & - & - \\
\hline Pressure support ventilation & $40(3.0)$ & $16(4.1)$ & $22(2.6)$ & $2(2.2)$ & - & - \\
\hline $\begin{array}{l}\text { Synchronized intermittent mandatory } \\
\text { ventilation }\end{array}$ & $389(29.6)$ & $108(27.8)$ & $255(30.5)$ & $26(29.2)$ & - & - \\
\hline Airway pressure release ventilation & $3(0.2)$ & $0(0.0)$ & $1(0.1)$ & $2(2.2)$ & - & - \\
\hline $\begin{array}{l}\text { Pressure regulated volume-controlled } \\
\text { ventilation }\end{array}$ & $68(5.2)$ & $14(3.6)$ & $48(5.7)$ & $6(6.7)$ & - & - \\
\hline Other & $5(0.4)$ & $0(0.0)$ & $5(0.6)$ & $0(0.0)$ & - & - \\
\hline Ppeak $\left(\mathrm{cmH}_{2} \mathrm{O}\right)$ & $22[18,28]$ & $21.0[18,25]$ & $22[18,28]$ & $28[23,36]$ & 0.0009 & $<0.0001$ \\
\hline Pplat $\left(\mathrm{cmH}_{2} \mathrm{O}\right) \dagger$ & $18[15,21]$ & $16[14,18]$ & $18[16,21]$ & $28[22,30]$ & $<0.0001$ & $<0.0001$ \\
\hline Driving pressure $\left(\mathrm{cmH}_{2} \mathrm{O}\right)$ & $14[11,18]$ & $13[10,17]$ & $15[11,18]$ & $16[14,20]$ & 0.0705 & 0.0037 \\
\hline Set RR (bpm) & $14[12,16]$ & $14[12,16]$ & $14[14,16]$ & $17[14,22]$ & 0.0011 & $<0.0001$ \\
\hline Measured RR (bpm) & $18[15,22]$ & $16[14,20]$ & $18[15,22]$ & $20[16,25]$ & $<0.0001$ & $<0.0001$ \\
\hline $\mathrm{FiO}_{2}(\%)$ & $50[40,60]$ & $40[40,50]$ & $50[40,60]$ & $80[60,100]$ & $<0.0001$ & $<0.0001$ \\
\hline Oxygen partial pressure/ $\mathrm{FiO}_{2}(\mathrm{mmHg})$ & $258[157,378]$ & $311[229,419]$ & $253[151,375]$ & $112[76,211]$ & $<0.0001$ & $<0.0001$ \\
\hline $\begin{array}{l}\text { Pulse oxymetric saturation of } \\
\text { haemoglobin/ } / \mathrm{FiO}_{2}\end{array}$ & $200[155,250]$ & $245[194,250]$ & $200[150,245]$ & $119[95,167]$ & $<0.0001$ & $<0.0001$ \\
\hline Arterial $\mathrm{pH}$ level & $7.3[7.3,7.4]$ & $7.4[7.3,7.4]$ & $7.3[7.2,7.4]$ & $7.3[7.2,7.4]$ & $<0.0001$ & $<0.0001$ \\
\hline Carbon dioxide partial pressure $(\mathrm{mmHg})$ & $36[31,43]$ & $35[29,40]$ & $37[31,44]$ & $41[34,52]$ & 0.0020 & $<0.0001$ \\
\hline Use of neuromuscular blockers (\%) & 225/1,306 (17.2) & 74/385 (19.2) & 117/382 (14.1) & 34 (38.2) & 0.0267 & $<0.0001$ \\
\hline Use of prone positioning (\%) & $6(0.5)$ & $0(0.0)$ & $0(0.0)$ & $6(6.7)$ & - & $<0.0001$ \\
\hline Use of recruitment maneuvers (\%) & $24(1.8)$ & $0(0.0)$ & $8(1.0)$ & $16(18.0)$ & 0.120 & $<0.0001$ \\
\hline Tracheostomy & $95(7.2)$ & $34(8.7)$ & 49 (5.9) & $12(13.5)$ & 0.080 & 0.0118 \\
\hline
\end{tabular}

ARDS, and most patients without ARDS received a $V_{T}$ under $10 \mathrm{~mL} / \mathrm{kg}$ PBW. Progression to ARDS was observed in one in every 25 patients. Patients with ARDS received higher PEEP than those not having ARDS. Pulmonary complications were frequent and occur more often in patients with ARDS. Crude ICU mortality was markedly different between patients with LIPS $<4$ versus patients with LIPS $\geq 4$ or with ARDS.

Considerable geographic variation was present in the proportion of patients with LIPS $\geq 4$ for ARDS and patients with ARDS. The disparity may be explained by differences in case mixes attributable to factors such as admission policies, season of enrolment, and availability of ICU beds. A cutoff of four for the LIPS was used to define the population at risk for developing ARDS. ${ }^{13}$ This cutoff has been used before in several other cohorts, albeit with limited success. ${ }^{7,15}$ Using other, higher cutoffs, unfortunately, did not improve its accuracy. ${ }^{7,15}$ The proportion of patients with ARDS on admission reported here is similar to the preceding PRoVENT study that was performed in high-income countries, ${ }^{7}$ but much lower than the $22 \%$ ARDS prevalence on day 1 or 2 observed in LUNG SAFE. ${ }^{8}$ Several factors could explain this disparity. There could be a difference in the risk for ARDS. Another factor could be the difference in access to mechanical ventilation. Whereas under-recognition of ARDS may occur in settings studied in the current study, there may have been over-recognition of ARDS by the computer algorithm used in LUNG SAFE. ${ }^{21}$

The proportion of patients receiving protective ventilation is comparable to findings reported in two recent investigations, ${ }^{7,8}$ challenging the hypothesis that delivering lung protective ventilation is less feasible in more resource-limited settings. These encouraging results in terms of ventilator management, and the fact that ventilator settings were not associated with mortality or pulmonary complications, suggest other variables should also be explored to improve outcome of ventilated patients in resource-limited ICUs. Patients with ARDS were more frequently receiving ventilation with protective settings. In fact, $V_{T}$ in patients with ARDS in these ICUs from Asian 


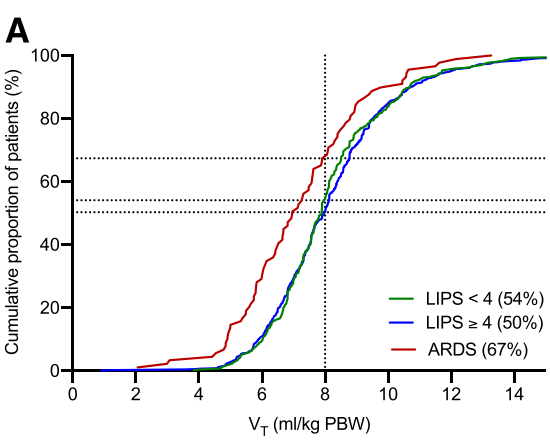

C

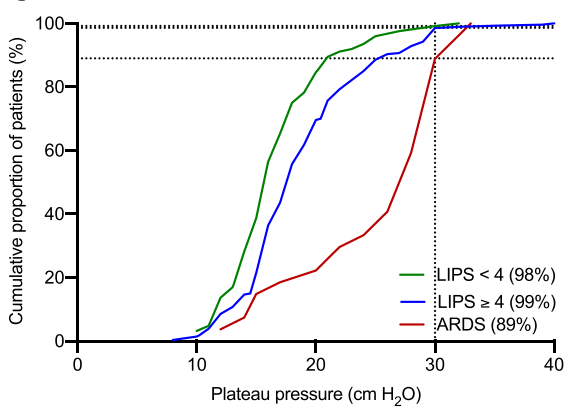

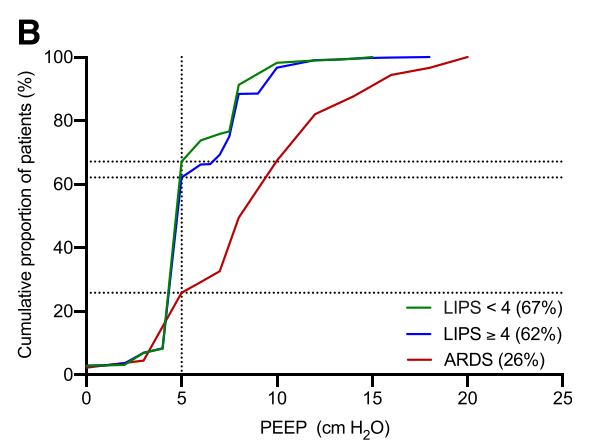

D

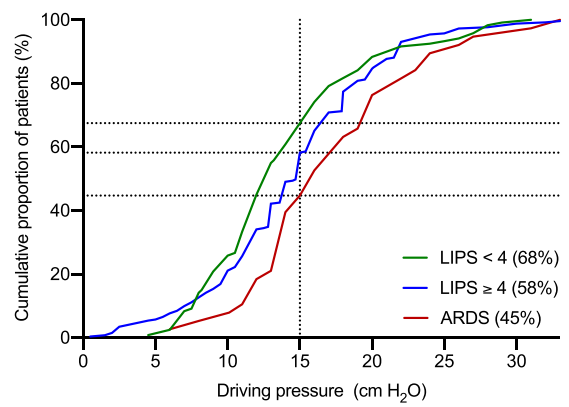

FIGURE 2. Ventilation parameters at admission in patients with LIPS $<4$ vs. patients with LIPS $\geq 4$ and those with ARDS cumulative frequency distribution of (A) $V_{T}$, (B) PEEP, (C) plateau pressure, and (D) driving pressure. Vertical dotted lines represent the cutoff for each variable, and horizontal dotted lines represent the respective proportion of patients reaching each cutoff. Cutoffs for ventilator parameters were like those used in previous published reports on invasive ventilation practices, that is, $8 \mathrm{~mL} / \mathrm{kg} \mathrm{PBW}$ for $V_{T}, 5 \mathrm{cmH}_{2} \mathrm{O}$ for PEEP, $30 \mathrm{cmH}_{2} \mathrm{O}$ for Pplat, and $15 \mathrm{cmH} \mathrm{C}_{2} \mathrm{O}$ for driving pressure. ${ }^{7}$ ARDS = acute respiratory distress syndrome; $\mathrm{PBW}=$ predicted body weight; $\mathrm{PEEP}=$ positive end-expiratory pressure; $V_{T}=$ tidal volume. This figure appears in color at www.ajtmh.org.

middle-income countries was lower than that in those in LUNG SAFE. ${ }^{8}$ This could suggest a better implementation of protective ventilation in these settings, ${ }^{5,10}$ but may also point to a better titration of $V_{T}$ in clinically recognized ARDS. The improved ventilation settings in physician-recognized ARDS were also observed in LUNG SAFE, ${ }^{8}$ emphasizing the possibility that clinical recognition can drive behavioral change.

PRactice of VENTilation in Middle-income Countries shows there is scant individualization in ventilation, similar to previous investigations. ${ }^{3,4,7}$ Indeed, although median and mode $V_{T}$ were 450 and $500 \mathrm{~mL}$, there was a large variance in $V_{T}$ expressed as $\mathrm{mL} / \mathrm{kg}$ PBW. The median $V_{T}$ in terms of $\mathrm{mL} / \mathrm{kg}$ PBW was very similar to that in another multinational cohort, ${ }^{7}$ possibly denoting consideration for the lower average height and thus the PBW in this population of Asian individuals. Tidal volume based on actual body weight (ABW) was consistently lower than the one calculated using PBW, and it is possible several physicians still used $A B W$ to decide on the $V_{T}$ to apply. The fact that $V_{T}$ differences among groups were not significant after accounting for clustering indicates that titration of $V_{T}$ in ARDS did receive more attention in some participating centers. Despite well-contained $V_{T}$, the calculated driving pressure often reached suboptimal ranges associated with increased lung injury. This parameter, however, could only be calculated in one-third of patients, and Pmax may overestimate Pplat in patients under pressure-controlled ventilation. These findings are important as protective ventilation impacts survival of ICU patients., ${ }^{4,22-26}$

Most of the patients received a PEEP $\geq 5 \mathrm{cmH}_{2} \mathrm{O}$, in agreement with a well-documented global upward trend in the application of PEEP. ${ }^{4}$ Positive end-expiratory pressure did not differ between patients with LIPS $<4$ versus patients with LIPS $\geq 4$, but was higher in ARDS. Higher PEEP is mostly used in patients with ARDS, and especially in clinician-recognized ARDS, ${ }^{8}$ as was the case of this study. The low rate of use of recruitment maneuvers and prone positioning, mostly observed in ARDS patients in this cohort, is in line with the data reported by LUNG SAFE. ${ }^{8}$

Based on LIPS, two-thirds of patients were "at risk for ARDS," which is twice as high as in high-income countries. ${ }^{7}$ The proportion of patients with LIPS $\geq 4$ who developed ARDS during follow-up, however, was less than that reported in previous studies in high-income settings (7-9\%) ${ }^{7,27}$ and also compared with a recent investigation focusing on the development of ARDS in patients in Peruvian ICUs (11\%). ${ }^{28}$ The current study confirms the poor predictive value of the LIPS for developing $\mathrm{ARDS}^{7}$ and for pulmonary complications, however, did identify patients at increased risk of death. The higher mortality in the group with LIPS $\geq 4$ may be explained, at least in part by differences in age, Body mass index and comorbidities, the SOFA score on admission, and use of noninvasive ventilation before the start of invasive ventilation. Use of noninvasive ventilation was even independently associated with mortality, in line with findings of previous studies in patients receiving invasive ventilation. ${ }^{4,29}$

Intensive care unit mortality was considerably lower than that in other cohort studies from low- and middle-income countries (LMICs), ${ }^{10,11,30}$ an improvement that mirrors global trends. ${ }^{4}$ The benefit in terms of mortality reduction attributable to a wider implementation of protective ventilation is unknown, but possibly significant. This role is important as protective ventilation represents an intervention relatively 

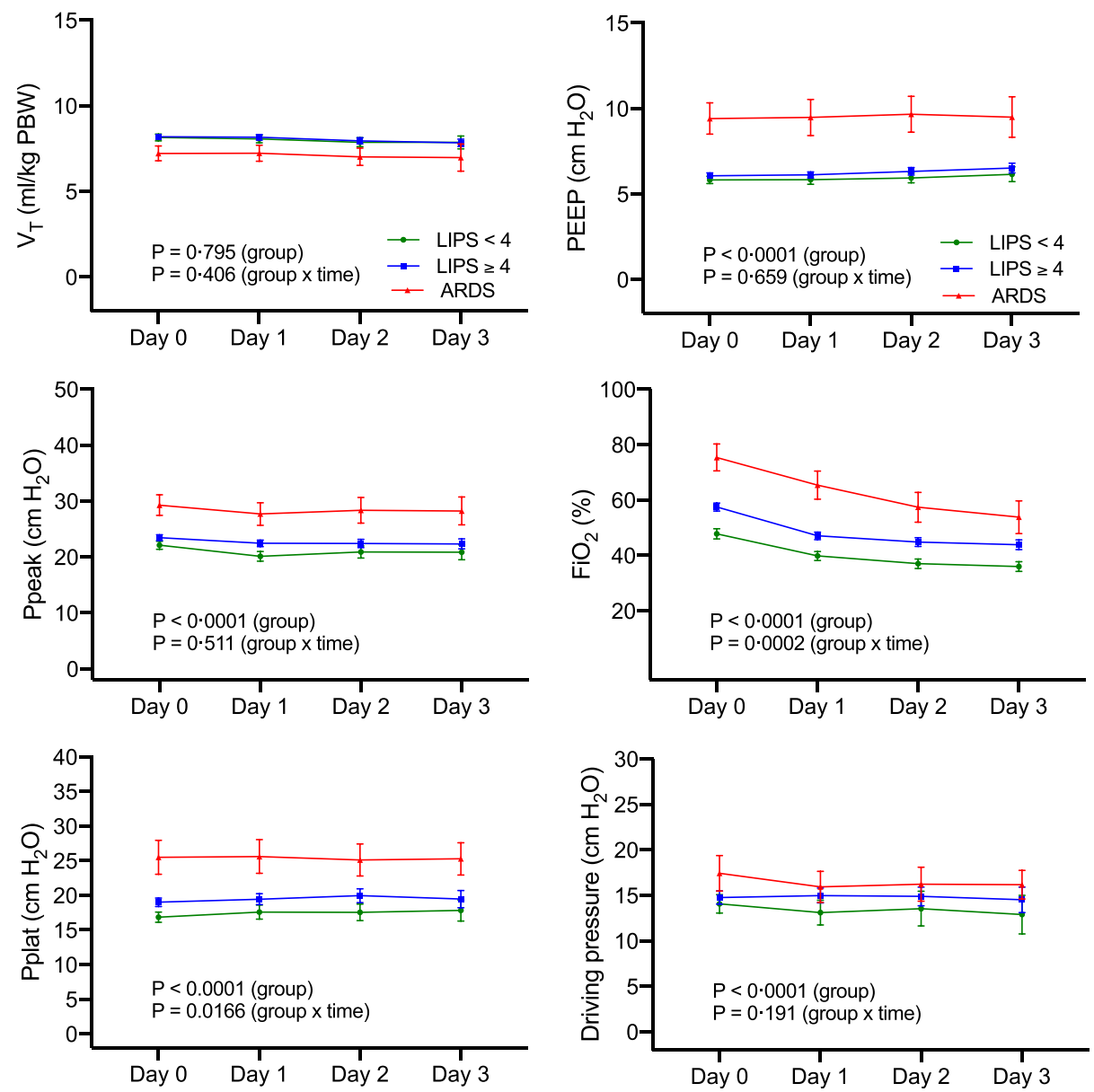

FIGURE 3. Ventilatory parameters in the first 4 days of mechanical ventilation. Lines are means and $95 \% \mathrm{Cls}$. $\mathrm{FiO}_{2}=$ fraction of inspired oxygen; $\mathrm{PBW}=$ predicted body weight; $\mathrm{PEEP}=$ positive end-expiratory pressure; $\mathrm{Ppeak}=$ peak pressure; $\mathrm{Pplat}=$ plateau pressure; $V_{T}=$ tidal volume. $P$-value is for group and time-group interaction. This figure appears in color at www.ajtmh.org.

independent of geo-economic variations between regions that are known to affect survival at least in ARDS. ${ }^{31}$ Intensive care unit mortality for the ARDS group was higher than that reported by the LUNG SAFE study, ${ }^{8}$ reflecting geo-economic effects on patients' outcomes. ${ }^{31}$

This study has several limitations. First, the willingness to participate may have facilitated a selection bias toward centers with awareness concerning protective ventilation and with more affluent resources. Second, as in any prospective observational study, reporting and observer bias or interference with daily practice cannot be excluded. Third, to limit the investigators' burden, granular data were limited to the first 4 days of ventilation. This limited information regarding end of ventilation in a quarter of the study cohort. Similarly, extrapulmonary complications which could have included unknown confounders were not captured. Follow-up was also limited to ICU discharge, limiting the available information on post-ICU patient outcomes. Also, no data were collected on the weaning process, which will be investigated in a separate multicenter study. ${ }^{32}$ Because of missing data, in the competing risk regression, we could not account for extubations due to life-sustaining therapy withdrawal caused by medical decisions, or by economic restraints of the patient entourage. Access to patients' data was restricted to local investigators and not externally monitored; thus, inclusion of all consecutive ventilated patients was not confirmed independently. Fourth, overrepresentation of some countries and seasonal differences could not be averted, as the number of centers per country or the 4-week study window was not limited by protocol. Finally, although definitions for pulmonary complications were prepublished and provided to national and local coordinators in local meetings, no formal site training was performed to homogenize complications scoring.

Strengths of this study include the wide variety of settings and participating ICUs, increasing the generalizability of results. The prospective design assured completeness of data collection, whereas the short time frame within which data were collected limited the effect of practice changes during study period. The focus on Asian LMICs allowed us to study a large region that has thus far been underrepresented in ventilation studies, ${ }^{4,7,8}$ whereas this region harbors half of the world population.

In conclusion, PRoVENT-iMiC extends the context-specific knowledge of ventilation practices in Asian middle-income countries, showing alignment with other world regions with regard to ventilation management and outcomes. However, the study also suggests areas for quality improvement initiatives and subjects for clinical trials, instrumental to enhance safety, and effectiveness of invasive ventilation in middleincome countries. 
TABLE 3

Pulmonary complications observed in first 7 days of mechanical ventilation and clinical outcomes

\begin{tabular}{|c|c|c|c|c|c|c|}
\hline & All patients $(n=1,315)$ & LIPS $<4(n=389)$ & LIPS $\geq 4(n=837)$ & $\operatorname{ARDS}(n=89)$ & $P$-value LIPS $<4$ vs. LIPS $\geq 4$ & $P$-value ${ }^{*}$ \\
\hline \multicolumn{7}{|l|}{ Pulmonary complications, $n(\%)$} \\
\hline $\begin{array}{l}\text { Patients with at least one new } \\
\text { pulmonary complicationt }\end{array}$ & $283(21.5)$ & $72(18.5)$ & $177(21.1)$ & $34(38.2)$ & 0.321 & 0.0002 \\
\hline \multicolumn{7}{|l|}{ Pulmonary complication type, $n(\%)$} \\
\hline Pulmonary infection & $110(8.4)$ & $34(8.7)$ & $65(7.8)$ & $11(12.4)$ & 0.638 & 0.314 \\
\hline ARDS & $51(3.9)$ & $11(2.8)$ & $40(4.8)$ & - & 0.151 & - \\
\hline Pneumothorax & $10(0.8)$ & $1(0.3)$ & $8(1.0)$ & $1(1.1)$ & 0.330 & 0.340 \\
\hline Pleural effusion & $44(3.3)$ & $6(1.5)$ & $35(4.2)$ & $3(3.4)$ & 0.0263 & 0.057 \\
\hline Atelectasis & $62(4.7)$ & $14(3.6)$ & $41(4.9)$ & 7 (7.9) & 0.382 & 0.212 \\
\hline Cardiogenic pulmonary edema & $28(2.1)$ & $6(1.5)$ & $20(2.4)$ & $2(2.2)$ & 0.456 & 0.631 \\
\hline New pulmonary infiltrates & $72(5.5)$ & $21(5.4)$ & $40(4.8)$ & 11 (12.4) & 0.747 & 0.012 \\
\hline \multicolumn{7}{|l|}{ Outcomes } \\
\hline Death in ICU & $388 / 1,300(29.8)$ & $66 / 383(17.2)$ & 282/828 (34.1) & $40(44.9)$ & $<0.0001$ & $<0.0001$ \\
\hline Death during ICU stay & $362 / 1,300(27.8)$ & 60/383 (15.7) & 265/828 (32.0) & $37(41.6)$ & $<0.0001$ & $<0.0001$ \\
\hline Palliative care & $26(2.0)$ & $6(1.6)$ & $17(2.1)$ & $3(3.4)$ & 0.726 & 0.540 \\
\hline Duration of MV (days) & $2.0[1.0,5.0]$ & $2.0[1.0,5.0]$ & $2.0[1.0,5.0]$ & $4.0[2.0,8.0]$ & 0.925 & 0.0024 \\
\hline Re-intubation & $52(4.0)$ & $16(4.1)$ & $34(4.1)$ & $2(2.2)$ & 1.00 & 0.693 \\
\hline Length of stay in ICU (days) & $4.0[2.0,7.0]$ & $3.0[2.0,7.0]$ & $4.0[2.0,7.0]$ & $5.0[2.0,9.0]$ & 0.187 & 0.0641 \\
\hline Length of stay in survivors & $4.0[2.0,7.0]$ & $3.0[2.0,7.0]$ & $4.0[2.0,7.0]$ & $6.0[3.0,9.0]$ & 0.001 & 0.0001 \\
\hline Length of stay in non-survivors & $3.0[1.0,7.0]$ & $3.0[2.0,8.0]$ & $3.0[1.0,6.0]$ & $3.0[2.0,8.0]$ & 0.122 & 0.239 \\
\hline Ventilator-free days at day $28 \ddagger$ & $24.0[0.0,27.0]$ & $26.0[16.5,27.0]$ & $23.0[0.0,27.0]$ & $8.0[0.0,24.5]$ & $<0.0001$ & $<0.0001$ \\
\hline \multicolumn{7}{|l|}{ Type of discharge for survivors } \\
\hline Transferred to ward & 689/1,300 (53.0) & 257/383 (67.1) & $399 / 828$ (48.2) & $33(37.1)$ & $<0.0001$ & $<0.0001$ \\
\hline Discharged home & $46 / 1,300(3.5)$ & $11 / 383(2.9)$ & $32 / 828(3.9)$ & $3(3.4)$ & 0.483 & 0.683 \\
\hline Transferred to other ICU & $40 / 1,300(3.1)$ & $14 / 383(3.7)$ & $25 / 828(3.0)$ & $1(1.1)$ & 0.683 & 0.454 \\
\hline Transferred to intermediate care & 137/1,300 (10.5) & $35 / 383(9.1)$ & 90/828 (10.9) & 12 (13.5) & 0.413 & 0.425 \\
\hline
\end{tabular}

ARDS = acute respiratory distress syndrome; ICU = intensive care unit. Data are number of patients/total number of patients (\%) or median [IQR].

${ }^{\star} P$-value represents comparison across the three study groups for each variable.

† Pulmonary complications diagnosed on the first 24 of invasive ventilation were excluded from analysis and reported separately.

$\ddagger$ In patients who died while receiving invasive mechanical ventilation, invasive ventilation-free days are counted as 0 . Patients discharged alive from ICU were assumed to be alive at day 28.

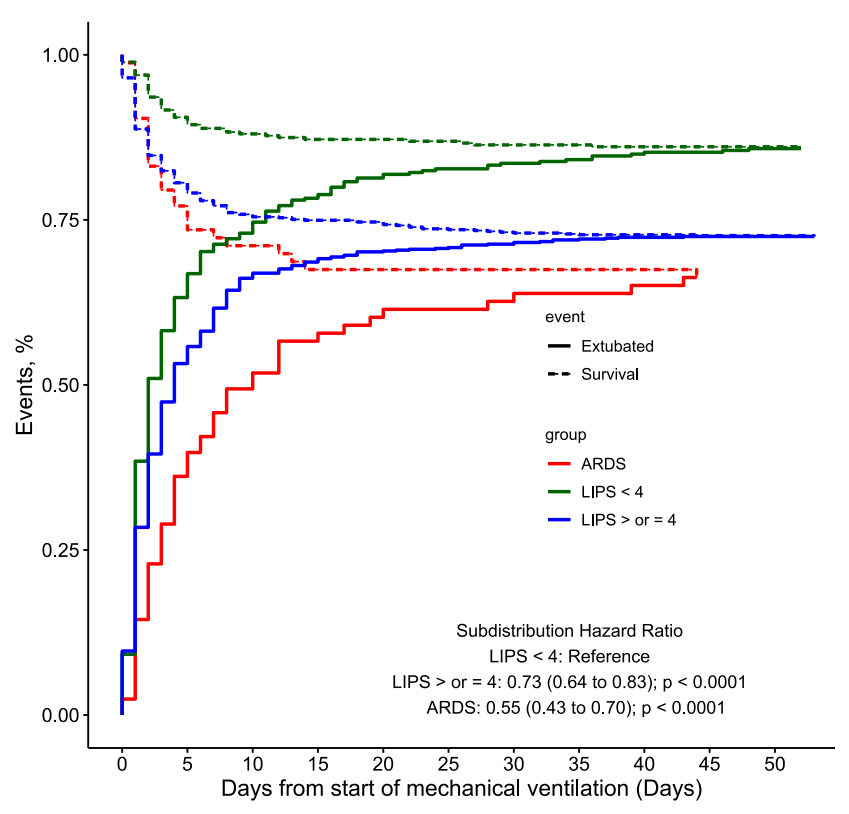

FIGURE 4. Probability of discontinuing mechanical ventilation when accounting for the competing risk of death before extubation in patients with LIPS $<4$ vs. patients with LIPS $\geq 4$ and those with ARDS estimates is shown as hazard ratio $(95 \% \mathrm{Cls})$. The cumulative incidence function curves estimate the instantaneous probability over time of extubation (shown in continuous lines) when accounting for the risk set attrition due to the occurrence of the competing risk (death before extubation, shown in survival curves as dotted lines). The "Fine and Gray" proportional sub-distribution hazards analysis was used to model the sub-distribution hazard and derive $P$-values. ARDS $=$ acute respiratory distress syndrome. This figure appears in color at www.ajtmh.org.
Received September 10, 2020. Accepted for publication November 22, 2020.

Published online January 11, 2021.

Note: Supplemental appendix, tables, and figures appear at www.ajtmh.org.

PRoVENT-iMiC, "PRactice of VENTilation in Middle-income Countries"

MORU, "Mahidol-Oxford Tropical Medicine Research Unit", Bangkok, Thailand (www.tropmedres.ac)

PROVE Network, "PROtective VEntilation Network" (www.provenet.eu)

Members of the PRoVENT-iMiC Steering Committee: Luigi Pisani (Mahidol-Oxford Tropical Medicine Research Unit, Bangkok, Thailand; Amsterdam University Medical Centers, Location AMC, Amsterdam, The Netherlands); Ary Serpa Neto (Amsterdam University Medical Centers, Location AMC, Amsterdam, The Netherlands; Hospital Israelita Albert Einstein, São Paulo, Brazil); Anna Geke Algera (Amsterdam University Medical Centers, Location AMC, Amsterdam, The Netherlands); Salvatore Grasso (Bari University Policlinic Hospital, University of Bari, Bari, Italy); Frederique Paulus (Amsterdam University Medical Centers, Location AMC, Amsterdam, The Netherlands); Marcelo Gama de Abreu (University Hospital Carl Gustav Carus, and Technical University Dresden, Dresden, Germany); Paolo Pelosi (San Martino Policlinico Hospital IRCCS for Oncology, University of Genoa, Genoa, Italy); Arjen M. Dondorp (Mahidol University, Bangkok, Thailand); Marcus J. Schultz (Mahidol-Oxford Tropical Medicine Research Unit, Bangkok, Thailand; Amsterdam University Medical Centers, Location AMC, Amsterdam, The Netherlands; University of Oxford, Oxford, United Kingdom).

Members of the PRoVENT-iMiC Writing Committee: Luigi Pisani (Mahidol-Oxford Tropical Medicine Research Unit, Bangkok, Thailand; Amsterdam University Medical Centers, Location AMC, Amsterdam, The Netherlands); Ary Serpa Neto (Hospital Israelita Albert Einstein, São Paulo, Brazil; and Faculdade de Medicina do ABC, Santo André, Brazil); Arjen M. Dondorp (Mahidol-Oxford Tropical Medicine Research Unit, Bangkok, Thailand); Marcus J. Schultz (Mahidol-Oxford Tropical Medicine Research Unit, Bangkok, Thailand; Amsterdam University Medical Centers, Location AMC, 
TABLE 4

Analysis of factors associated with intensive care unit mortality in patients receiving mechanical ventilation

\begin{tabular}{|c|c|c|c|c|}
\hline \multirow[b]{2}{*}{ Clinical characteristics and comorbidities } & \multicolumn{2}{|c|}{ Unadjusted analyses } & \multicolumn{2}{|c|}{ Multivariable analyses } \\
\hline & Odds ratio $(95 \% \mathrm{Cl})$ & $P$ value & Odds ratio $(95 \% \mathrm{Cl})$ & $P$ value \\
\hline \multicolumn{5}{|l|}{ Age (years) } \\
\hline$\leq 65$ & 1 (reference) & & 1 (reference) & \\
\hline$>65$ & $1.37(1.02-1.85)$ & 0.038 & $1.72(1.18-2.51)$ & 0.005 \\
\hline Gender, female & $1.07(0.82-1.39)$ & 0.628 & - & - \\
\hline Body mass index $\left(\mathrm{kg} / \mathrm{m}^{2}\right)$ & $0.99(0.86-1.13)$ & 0.844 & - & - \\
\hline Hypertension & $1.15(0.88-1.50)$ & 0.300 & - & - \\
\hline Diabetes mellitus & $1.31(0.98-1.73)$ & 0.064 & $1.04(0.73-1.48)$ & 0.827 \\
\hline Heart failure & $0.74(0.43-1.25)$ & 0.259 & - & - \\
\hline Chronic kidney disease & $1.02(0.49-1.46)$ & 0.938 & - & - \\
\hline Chronic liver failure & $2.64(1.43-4.88)$ & 0.002 & $1.78(0.84-3.79)$ & 0.133 \\
\hline Chronic obstructive pulmonary disease & $0.63(0.35-1.11)$ & 0.109 & $0.60(0.30-1.20)$ & 0.149 \\
\hline Cancer & $1.22(0.76-1.96)$ & 0.406 & - & - \\
\hline \multicolumn{5}{|l|}{ Severity of illness } \\
\hline SOFA total & $2.14(1.85-2.49)$ & $<0.001$ & - & - \\
\hline Non-pulmonary SOFA & $2.05(1.78-2.38)$ & $<0.001$ & $1.65(1.37-2.00)$ & $<0.001$ \\
\hline Pulmonary SOFA & $1.31(1.15-1.50)$ & $<0.001$ & $1.09(0.89-1.33)$ & 0.401 \\
\hline Lung injury prediction score & $1.86(1.61-2.15)$ & $<0.001$ & $1.41(1.16-1.72)$ & 0.001 \\
\hline \multicolumn{5}{|l|}{ Management } \\
\hline $\begin{array}{l}\text { Tidal volume (mL/kg Predicted body } \\
\text { weight) }\end{array}$ & $0.89(0.77-1.03)$ & 0.124 & $0.89(0.74-1.08)$ & 0.237 \\
\hline $\begin{array}{l}\text { Positive end-expiratory pressure } \\
\left(\mathrm{cmH}_{2} \mathrm{O}\right)\end{array}$ & $1.10(1.04-1.16)$ & 0.001 & & \\
\hline$<8 \mathrm{cmH}_{2} \mathrm{O}$ & 1 (reference) & & 1 (reference) & \\
\hline $8-12 \mathrm{cmH}_{2} \mathrm{O}$ & $1.52(1.02-2.26)$ & 0.037 & $0.82(0.51-1.34)$ & 0.434 \\
\hline$\geq 12 \mathrm{cmH}_{2} \mathrm{O}$ & $2.47(1.37-4.45)$ & 0.002 & $0.72(0.33-1.57)$ & 0.408 \\
\hline $\begin{array}{l}\text { Use of noninvasive ventilation before } \\
\text { intubation }\end{array}$ & $1.53(1.03-2.25)$ & 0.031 & $1.82(1.12-2.96)$ & 0.015 \\
\hline Ventilated in ward before admission & $1.47(0.93-2.30)$ & 0.095 & $1.07(0.62-1.86)$ & 0.803 \\
\hline Maximum airway pressure $\left(\mathrm{cmH}_{2} \mathrm{O}\right)$ & $1.53(1.30-1.79)$ & $<0.001$ & $1.26(1.03-1.55)$ & 0.027 \\
\hline Driving pressure $\left(\mathrm{cmH}_{2} \mathrm{O}\right)$ & $1.43(1.10-1.88)$ & 0.008 & - & - \\
\hline $\begin{array}{l}\text { Respiratory rate (movements per } \\
\text { minute) }\end{array}$ & $1.42(1.22-1.66)$ & $<0.001$ & $1.13(0.94-1.38)$ & 0.210 \\
\hline $\mathrm{FiO}_{2}(\%)$ & $1.74(1.51-2.01)$ & $<0.001$ & - & - \\
\hline \multicolumn{5}{|l|}{ Laboratory parameters } \\
\hline $\mathrm{PaO}_{2} / \mathrm{FiO}_{2}(\mathrm{mmHg})^{*}$ & $0.67(0.57-0.78)$ & $<0.001$ & - & - \\
\hline $\mathrm{PaCO}_{2}(\mathrm{mmHg})$ & $1.10(0.96-1.26)$ & 0.157 & $0.91(0.75-1.11)$ & 0.342 \\
\hline $\mathrm{HCO}_{3}(\mathrm{mEq} / \mathrm{L})$ & $0.68(0.59-0.79)$ & $<0.001$ & - & - \\
\hline $\mathrm{pH}^{*}$ & $0.63(0.53-0.73)$ & $<0.001$ & $0.77(0.63-0.94)$ & 0.001 \\
\hline \multicolumn{5}{|l|}{ Vital signs } \\
\hline $\mathrm{SpO}_{2}(\%)$ & $0.71(0.61-0.83)$ & $<0.001$ & - & - \\
\hline $\mathrm{SpO}_{2} / \mathrm{FiO}_{2}(\mathrm{mmHg})^{\star}$ & $0.55(0.47-0.64)$ & $<0.001$ & - & - \\
\hline Heart rate $(\mathrm{bpm})^{\star}$ & $1.49(1.29-1.70)$ & $<0.001$ & $1.27(1.06-1.52)$ & 0.008 \\
\hline Mean arterial pressure $(\mathrm{mmHg})^{\star}$ & $0.65(0.56-0.75)$ & $<0.001$ & $0.85(0.71-1.02)$ & 0.080 \\
\hline \multicolumn{5}{|l|}{ Pulmonary complications } \\
\hline $\begin{array}{l}\text { Occurrence of at least one } \\
\text { complication }\end{array}$ & $1.18(0.86-1.61)$ & 0.311 & - & - \\
\hline
\end{tabular}

Amsterdam, The Netherlands, University of Oxford, Oxford, United Kingdom).

PRactice of VENTilation in Middle-income Countries collaborators by COUNTRY (in alphabetical order)

BANGLADESH: AKM Shamsul Alam, Syeda Nafisa Khatoon, Ranjan Kumer Nath, Mohammed Abdur Rahman Chowdhury (Chittagong Medical College Hospital, Chittagong, Bangladesh); Debabrata Banik, Montosh Kumar Mondol, Sakibur Rahman Bhuiyan (Bangabandhu Sheikh Mujib Medical University, Dhaka, Bangladesh); Areef Ahsan, Suraiya Nazneen, Rozina Sultana, Tarikul Hamid (BIRDEM General Hospital, Dhaka, Bangladesh); Mozaffer Hossain, Syed Tariq Reza, Muhammad Asaduzzaman, Mohammad Salim, (Dhaka Medical College Hospital, Dhaka, Bangladesh); Abu Hena Mostafa Kamal, Sheikh Mohammed Taher, Taohidul Majid Taohid, Pranab Karmaker (Rajshahi Medical College Hospital, Rajshahi, Bangladesh); Sabyasachi Roy, Shantanu Das, Sohel Ahmed Sarkar, Monju Lal Dutta, Poulomi
Roy (Sylhet MAG Osmani Medical College Hospital, Sylhet, Bangladesh) - INDIA: Bhuvana Krishna, Sriram Sampath (St. John's Medical College, Bangalore); Chinni Krishna Kasi, Rajyabardhan Pattnaik, (Ispat General Hospital, Rourkela, India); Shiva lyer, Jignesh Shah (Bharati Vidyapeeth Medical College, Pune, India); Anand Dongre (Swastik Critical Care, Nagpur, India) - IRAN: Navid Nooraei (Modarres Hospital, Tehran, Iran); Reza Hashemian, Reza Raessi Estabragh, Majid Malekmohammad (Masih Daneshvari Hospital, Tehran, Iran); Batoul Khoundabi (Red Crescent Society of the Islamic Republic of Iran, Tehran, Iran); Maziar Mobasher (Tehran Pars Hospital, Tehran, Iran) - MALAYSIA: Nor'azim Mohd Yunos, Mahazir Kassim, Voon Chern Min, Stanis Sutharsa Das, Siti Nur Suhaila Azauddin, Dharshinie Dorasamy, (Hospital Sultanah Aminah Johor Bahru, Malaysia); Tai Li Ling (Hospital Kuala Lumpur, Kuala Lumpur, Malaysia); Mohd Basri Mat Nor, Nurhafizah Zarudin (International Islamic University Medical Centre, Kuantan, Malaysia); Mohd Shahnaz Hassan, Mohamad Fadhil Hadi Jamaluddin, Mohamad Irfan Bin Othman Jailani, (University of 
Malaya Medical Centre, Kuala Lumpur, Malaysia) - MALDIVES: Hassan Moosa, Hisham Ahmed Imad (Indira Gandhi Memorial Hospital, Malé, Maldives) - NEPAL: Gyan Kayastha, Aaradhana Adhikari, Raju Pangeni (Patan Academy of Health Sciences, Kathmandu, Nepal) PAKISTAN: Sonia Joseph (Allied Hospital, Faisalabad, Pakistan); Aftab Akhtar, Aayesha Qadeer (Shifa International Hospital, Islamabad, Pakistan); Iqbal Memon, Syed Muneeb Ali (Pakistan Institute of Medical Sciences, Islamabad, Pakistan); Farah Idrees, Saima Kamal (Aga Khan University, Karachi, Pakistan); Sadaf Hanif, Atta Ur Rehman (Patel Hospital, Karachi, Pakistan); Arshad Taqi, Tanveer Hussain (National Hospital and Medical Center, Lahore, Pakistan); Ahmed Farooq (Doctor's Hospital, Lahore, Pakistan); Saleh Khaskheli (Peoples Medical College Hospital, Nawabshah, Pakistan); Muhammad Hayat (North West General Hospital, Peshawar, Pakistan) - SRI LANKA: Upeka Samaranayake (Anuradhapura Teaching Hospital, Anuradhapura, Sri Lanka); S. Mathanalagan (Base Hospital, Batticaloa, Sri Lanka); Asoka Gunaratne (Colombo South Teaching Hospital, Colombo, Sri Lanka); Kanishka Indraratna, Nimangee Mithraratne, Kaushila Thilakasiri, Chamila Pilimatalawwe, Y. A. Hasitha Dilhani (General Hospital Sri Jayawardenapura, Colombo, Sri Lanka); Marie Fernando, Kumudini Ranatunge (National Hospital Sri Lanka - SICU, Colombo, Sri Lanka); Loranthi Samarasinghe, Manori Vaas (Lanka Hospital, Colombo, Sri Lanka); Manoj Edirisooriya (National Hospital Sri Lanka-MICU, Colombo, Sri Lanka); Chaturani Sigera (Network for improving Critical Care Systems and Training, Colombo, Sri Lanka); Janaki Arumoli (Jaffna Teaching Hospital, Jaffna, Sri Lanka); Kesharie De Silva (Karapitiya Teaching Hospital, Galle, Sri Lanka); Bimal Kudavidanage (Base Hospital, Kegalle, Sri Lanka); Visanthi Pinto (Peradenyia University Hospital, Peradenyia, Sri Lanka); Lakshman Dissanayake (Puttalam Base Hospital, Puttalam, Sri Lanka) - THAILAND: Napplika Kongpolprom (King Chulalongkorn Memorial Hospital, Chulalongkorn University, Bankgok, Thailand); Hisham Ahmed, Udomsak Silachamroon (Hospital for Tropical Diseases, Mahidol University, Bangkok, Thailand); Prapaporn Pornsuriyasak, Tananchai Petnak, Pongsasit Singhatas, Viratch Tangsujaritvijit (Ramathibodi Hospital, Bangkok, Thailand); Suthat Rungruanghiranya (Srinakharinwirot University, Ongkarak, Thailand); Annop Piriyapatsom (Sriraj Hospital, Bankok, Thailand); Kaweesak Chittawatanarat, Kanokkarn Juntaping (SICU, Department of Surgery, Faculty of Medicine, Chiang Mai University, Maharaj Nakorn Chiang Mai Hospital, Chiang Mai, Thailand); Konlawij Trongtrakul, Poungrat Thungtitikul (Vajira Hospital, Bangkok, Thailand); Pattraporn Tajarernmuang (Chiang Mai HospitalMICU, Chiang Mai, Thailand); Sunisa Chatmongkolchart, Rungsun Bhurayanontachai, Osaree Akaraborworn, Asma Navasakulpong (Prince of Songkla University, Hatyai, Thailand); Karjbundid Surasit (Nakornping Hospital, Chiang Mai, Thailand); - VIET NAM: Behzad Nadjm, Vu Quoc Dat, Nguyen Thi Thanh Ha, Nguyen Van Kinh (National Hospital for Tropical Diseases, Hanoi, Viet Nam); Duong Bich Thuy (Hospital for Tropical Diseases, Ho Chi Minh City, Vietnam); Lam Minh Yen, Louise Thwaites (Oxford University Clinical Research Unit, Ho Chi Minh City, Viet Nam).

Financial support: External funding source for this study was sought only in Vietnam (Wellcome Trust Grants 107367/Z/15/Z and 089276/ $\mathrm{B} / 09 / 7)$.

Disclosure: The members of the PRoVENT-iMiC Steering Committee and the national coordinators designed and overviewed the conduct of the study. PRoVENT-iMiC collaborators, consisting of national coordinators and local investigators, collected the data. This study report was written by the members of the PRoVENT-iMiC Writing Committee and revised by the PRoVENT-iMiC Steering Committee and all National Coordinators. L. P. and A. S. N. had complete access to all study data and performed the analyses, with support from A. M. D. and M. J. S. L. P., A. S. N., A. M. D., and M. J. S. made the final decision to submit the report for publication. L. P. was the study coordinator. L. P. and A. S. N. contributed equally to this study.

Authors' addresses: Luigi Pisani, Department of Intensive Care, Amsterdam University Medical Centers, Location AMC, Amsterdam, The Netherlands, and Mahidol Oxford Tropical Medicine Research Unit, Bangkok, Thailand, E-mail: luigipisani@gmail.com. Anna Geke Algera and Frederique Paulus, Department of Intensive Care, Amsterdam University Medical Centers, Location AMC, Amsterdam, The Netherlands, E-mails: a.g.algera@amsterdamumc.nl and f.paulus@amsterdamumc.nl. Ary Serpa Neto, Critical Care Medicine,
Hospital Israelita Albert Einstein, Sao Paulo, Brazil, E-mail: ary.neto2@ einstein.br. Areef Ahsan, Department of Critical Care, BIRDEM General Hospital, Dhaka, Bangladesh, E-mail: dr_asmareef@yahoo.com. Abigail Beane, Department of Malaria and Critical Illness, Mahidol Oxford Tropical Medicine Research Unit, Bangkok, Thailand, E-mail: abi@nicslk.com. Kaweesak Chittawatanarat, Department of Surgery, Chiang Mai University, Chiang Mai, Thailand, E-mail: kchittaw@ gmail.com. Abul Faiz, Department of Medicine, Sir Salimullah Medical College, Dhaka, Bangladesh, E-mail: drmafaiz@gmail.com. Rashan Haniffa, Network for Improving Critical Care Systems and Training, Colombo, Sri Lanka, and Mahidol-Oxford Tropical Medicine Research Unit (MORU), Mahidol University, Bangkok, Thailand, E-mail: rashan@ nicslk.com. Seyed MohammadReza Hashemian, Chronic Respiratory Diseases Research Center (CRDRC), Shahid Beheshti University of Medical Sciences, Tehran, Iran, E-mail: iran.criticalcare@yahoo.com. Madiha Hashmi, Department of Anaesthesiology, Aga Khan University, Karachi, Pakistan, E-mail: madiha@nicslk.com. Hisham Ahmed Imad, Department of Clinical Tropical Medicine, Faculty of Tropical Medicine, Mahidol University, Bangkok, Thailand, and Indira Gandhi Memorial Hospital, Malé, Maldives, E-mail: hisham.a.imad@ gmail.com. Kanishka Indraratna, Department of Intensive Care, Sri Jayewardenepura General Hospital, Colombo, Sri Lanka, E-mail: kanishka.indraratna@yahoo.com. Shivakumar lyer, Bharati Vidyapeeth University Medical College, Pune, India, E-mail: suchetashiva@ gmail.com. Gyan Kayastha, Department of Internal Medicine, Patan Academy of Health Science, Kathmandu, Nepal, E-mail: gyankayastha@pahs.edu.np. Bhuvana Krishna and Sriram Sampath, Department of Critical Care Medicine, St. John's Medical College, Bangalore, India, E-mails: bhuvana.11@gmail.com and sriram.sampath123@gmail.com. Tai Li Ling, Department of Anaesthesia and Intensive Care, Hospital Kuala Lumpur, Kuala Lumpur, Malaysia, E-mail: taililing@gmail.com. Hassan Moosa, Department of Intensive Care, Indira Gandhi Memorial Hospital, Malé, Maldives, E-mail: hmoosaster@gmail.com. Behzad Nadjm, National Hospital of Tropical Diseases, Oxford University Clinical Research Unit, Hanoi, Vietnam, E-mail: behzadnadjm@gmail.com. Rajyabardhan Pattnaik, Division of Critical Care Medicine, Ispat General Hospital, Rourkela, India, E-mail: rajyapattnaik@yahoo.co.in. Louise Thwaites, Hospital for Tropical Diseases, Oxford University Clinical Research Unit, Ho Chi Minh City, Vietnam, E-mail: Ithwaites@oucru.org. Ni Ni Tun, Naypyidaw unit, Medical Action Myanmar, Naypyidaw, Myanmar, E-mail: nini@mam.org.mm. Nor'azim Mohd Yunos, Jeffrey Cheat School of Medicine and Health Sciences, Monash University Malaysia, Johor Bahru, Malaysia, E-mail: norazim@ummc.edu.my. Salvatore Grasso, Department of Emergency and Organ Transplantation (DETO), Intensive Care Unit, University of Bari, Bari, Italy, E-mail: salvatore.grasso@uniba.it. Marcelo Gama de Abreu, Pulmonary Engineering Group, Department of Anaesthesiology and Intensive Care Medicine, University Hospital Carl Gustav Carus, and Technical University Dresden, Dresden, Germany, E-mail: mgabreu@uniklinikumdresden.de. Paolo Pelosi, Department of Surgical Sciences and Integrated Diagnostics, University of Genoa, Genoa, Italy, E-mail: ppelosi@hotmail.com. Nick Day, Nuffield Department of Medicine, Mahidol Oxford Tropical Medicine Research Unit, University of Oxford, Bangkok, Thailand, E-mail: nickd@tropmedres.ac. Nicholas J. White, Mahidol-Oxford Tropical Medicine Research Unit, Thailand, E-mail: nickw@tropmedres.ac. Arjen M. Dondorp, Faculty of Tropical Medicine, Mahidol-Oxford Tropical Medicine Research Unit (MORU), Bangkok, Thailand, E-mail: arjen@tropmedres.ac. Marcus J. Schultz, Department of Intensive Care, Amsterdam University Medical Centers, Location AMC, Amsterdam, The Netherlands, and Department of Malaria and Critical Care, Mahidol Oxford Tropical Medicine Research Unit, Bangkok, Thailand, E-mail: marcus.j.schultz@gmail.com.

This is an open-access article distributed under the terms of the Creative Commons Attribution (CC-BY) License, which permits unrestricted use, distribution, and reproduction in any medium, provided the original author and source are credited.

\section{REFERENCES}

1. Slutsky AS, Ranieri VM, 2014. Ventilator-induced lung injury. N Engl J Med 370: 980.

2. Esteban $A$ et al., 2002. Characteristics and outcomes in adult patients receiving mechanical ventilation: a 28 -day international study. JAMA 287: 345-355. 
3. Esteban A et al., 2008 Evolution of mechanical ventilation in response to clinical research. Am J Respir Crit Care Med 177: 170-177.

4. Esteban A et al., 2013. Evolution of mortality over time in patients receiving mechanical ventilation. Am J Respir Crit Care Med 188: 220-230.

5. Azevedo LC et al., 2013. Clinical outcomes of patients requiring ventilatory support in Brazilian intensive care units: a multicenter, prospective, cohort study. Crit Care 17: R63.

6. Brun-Buisson $\mathrm{C}$ et al., 2004. Epidemiology and outcome of acute lung injury in European intensive care units results from the ALIVE study. Intensive Care Med 30: 51-61.

7. Neto AS et al., 2016. Epidemiological characteristics, practice of ventilation, and clinical outcome in patients at risk of acute respiratory distress syndrome in intensive care units from 16 countries (PRoVENT): an international, multicenter, prospective study. Lancet Respir Med 4: 882-893.

8. Bellani G et al., 2016. Epidemiology, patterns of care, and mortality for patients with acute respiratory distress syndrome in intensive care units in 50 countries. JAMA 315: 2526-2533.

9. Acute Respiratory Distress Syndrome Network, 2000. Ventilation with lower tidal volumes as compared with traditional tidal volumes for acute lung injury and the acute respiratory distress syndrome. N Engl J Med 342: 1301-1308.

10. Karthikeyan B, Kadhiravan T, Deepanjali S, Swaminathan RP, 2015. Case-mix, care processes, and outcomes in medically-ill patients receiving mechanical ventilation in a low-resource setting from southern India: a prospective clinical case series. PLoS One 10: e0135336.

11. Inglis R, Ayebale E, Schultz MJ, 2019. Optimizing respiratory management in resource-limited settings. Curr Opin Crit Care 25: $45-53$.

12. Arabi YM et al., 2016. Structure, organization, and delivery of critical care in Asian ICUs*. Crit Care Med 44: e940-e948.

13. Pisani $L$ et al., 2018. PRactice of VENTilation in Middle-Income Countries (PRoVENT-iMIC): rationale and protocol for a prospective international multicenter observational study in intensive care units in Asia. BMJ Open 8: e020841.

14. Von Elm E et al., 2007. The Strengthening the Reporting of Observational Studies in Epidemiology (STROBE) statement: guidelines for reporting observational studies. Lancet 370: 1453-1457.

15. Gajic $O$ et al., 2011. Early identification of patients at risk of acute lung injury: evaluation of lung injury prediction score in a multicenter cohort study. Am J Respir Crit Care Med 183: 462-470.

16. ARDS Definition Task Force, 2012. Acute respiratory distress syndrome, the Berlin definition. JAMA 307: 2526-2533.

17. Riviello ED et al., 2016. Hospital incidence and outcomes of the acute respiratory distress syndrome using the Kigali modification of the Berlin definition. Am J Respir Crit Care Med 193: $52-59$.
18. Vercesi V et al., 2018. External confirmation and exploration of the Kigali modification for diagnosing moderate or severe ARDS. Intensive Care Med 44: 523-524.

19. Pisani L et al., 2017. Risk stratification using $\mathrm{SpO}_{2} / \mathrm{FiO}_{2}$ and $\mathrm{PEEP}$ at initial ARDS diagnosis and after $24 \mathrm{~h}$ in patients with moderate or severe ARDS. Ann Intensive Care 7: 108.

20. LAS VEGAS investigators, 2017. Epidemiology, practice of ventilation and outcome for patients at increased risk of postoperative pulmonary complications. Eur $J$ Anaesthesiol 34: 492-507.

21. Villar J, Schultz MJ, Kacmarek RM, 2016. The LUNG SAFE: a biased presentation of the prevalence of ARDS! Crit Care 20: 108.

22. Gajic O, Frutos-Vivar F, Esteban A, Hubmayr RD, Anzueto A, 2005. Ventilator settings as a risk factor for acute respiratory distress syndrome in mechanically ventilated patients. Intensive Care Med 31: 922-926.

23. Gajic $O$ et al., 2004. Ventilator-associated lung injury in patients without acute lung injury at the onset of mechanical ventilation. Crit Care Med 32: 1817-1824.

24. Serpa Neto A et al., 2012. Association between use of lungprotective ventilation with lower tidal volumes and clinical outcomes among patients without acute respiratory distress syndrome: a meta-analysis. JAMA 308: 1651

25. Sekiguchi H, Schenck LA, Horie R, Suzuki J, Lee EH, McMenomy BP, Chen TE, Lekah A, Mankad SV, Gajic O, 2015. Critical care ultrasonography differentiates ARDS, pulmonary edema, and other causes in the early course of acute hypoxemic respiratory failure. Chest 148: 912-918.

26. Rackley CR, Maclntyre NR, 2019. Low tidal volumes for everyone? Chest 156: 783-791.

27. Kor DJ et al., 2016. Effect of aspirin on development of ARDS in atrisk patients presenting to the emergency department the LIPSa randomized clinical trial. JAMA 315: 2406-2414.

28. Gupta $\mathrm{E}$ et al., 2019. Risk factors for the development of acute respiratory distress syndrome in mechanically ventilated adults in Peru: a multicenter observational study. Crit Care 23: 398.

29. Wunsch H, Linde-Zwirble WT, Angus DC, Hartman ME, Milbrandt EB, Kahn JM, 2010. The epidemiology of mechanical ventilation use in the United States. Crit Care Med 38: 1947-1953.

30. Sudarsanam TD, Jeyaseelan L, Thomas K, John G, 2005. Predictors of mortality in mechanically ventilated patients. Postgrad Med J 81: 780-783.

31. Laffey JG et al., 2017. Geo-economic variations in epidemiology, patterns of care, and outcomes in patients with acute respiratory distress syndrome: insights from the LUNG SAFE prospective cohort study. Lancet Respir Med 5: 627-638.

32. Heunks L, Bellani G, Pham T, Brochard L, Laffey JG, 2019. The worldwide assessment of separation of patients from ventilatory assistance (WEAN SAFE) ERS Clinical Research Collaboration. Eur Respir J 53: 1802228. 